\title{
Association between Deep Subcutaneous Adipose Tissue Estimated by DAAT Index and Dietary Intake in Patients with Acute Coronary Syndrome
}

\author{
Elana Stein, ${ }^{\circledR}$ Sandra Barbiero, ${ }^{2}{ }^{\circledR}$ Vera Lucia Portal, ${ }^{2}{ }^{\circledR}$ Victória da Luz, ${ }^{\circledR}$ Aline Marcadenti ${ }^{\circledR}$ \\ Universidade Federal de Ciências da Saúde de Porto Alegre (UFCSPA), ${ }^{\prime}$ Porto Alegre, RS - Brazil \\ Instituto de Cardiologia/Fundação Universitária de Cardiologia (IC/FUC), ${ }^{2}$ Porto Alegre, RS - Brazil \\ Hospital do Coração, ${ }^{3}$ São Paulo, SP - Brazil
}

\section{Abstract}

Background: Abdominal obesity has been associated with cardiovascular disease and may be modulated by dietary intake. The deep abdominal subcutaneous adipose tissue (dSAT) is a body fat compartment that can be estimated by using mathematical formulas.

Objectives: To evaluate the association between dSAT estimated by the Deep-Abdominal-Adipose-Tissue (DAAT) index and dietary intake in patients with acute coronary syndrome (ACS).

Methods: This is a cross-sectional study conducted with patients $\geq 18$ years of age admitted to a tertiary hospital. Sociodemographic, clinical, and anthropometric (body weight [kg], height [m], waist, hip and neck circumferences $[\mathrm{cm}])$ data were evaluated. A food frequency questionnaire was applied to identify each patient's nutrient intake. The DAAT index was calculated according to specific formulas for men and women. Possible association between food intake and the DAAT index was evaluated by multiple linear regression. The level of significance adopted was 0.05 .

Results: This study evaluated 138 patients, with a mean age of $61.2 \pm 10.8$ years. Prevalence of obesity was $29.4 \%$ in men and $37.7 \%$ in women. Regarding waist circumference, $83 \%$ of the women showed values considered to be very high. The DAAT index was significantly higher in men when compared to woman $(\mathrm{P}<0.0001)$ and proved to be positively correlated with proteins $(\mathrm{r}=0.22, \mathrm{P}=0.01)$ and monounsaturated fatty acid $(\mathrm{r}=0.18, \mathrm{P}=0.04)$ intake in the entire sample. After adjustment for sex, alcohol consumption, and levels of physical activity, the DAAT index was associated with the female $\operatorname{sex}(B=-129.84, \mathrm{P}<0.001)$ and a sedentary lifestyle $(\mathrm{B}=57.99, \mathrm{P}<0.001)$.

Conclusion: dSAT estimated by the DAAT index was not associated with dietary intake in patients with ACS.

Keywords: Cardiovascular Diseases; Myocardial infarction; Subcutaneous Fat; Abdominal obesity; Diet.

\section{Introduction}

According to the World Health Organization (WHO), in recent decades, cardiovascular diseases (CVD) accounted for $30 \%$ of the world's deaths. ${ }^{1}$ Among CVDs, acute coronary syndrome (ACS) - represented by acute myocardial infarction, unstable angina, and sudden death, ${ }^{2}$ is the most prevalent. ACS is influenced by non-modifiable and modifiable risk factors, ${ }^{3}$ the most important of which are inadequate diet ${ }^{4,5}$ and sedentary lifestyle ${ }^{5,6}$ which also interfere in body adiposity.
Central adiposity is associated with the development of CVD. ${ }^{4}$ The abdominal region has two compartments of adipose tissue: visceral adipose tissue (VAT), already known for its association with $\mathrm{CVD},{ }^{7}$ and subcutaneous adipose tissue (SAT), subdivided into two functionally different compartments: ${ }^{8}$ superficial SAT (sSAT) and deep SAT (dSAT). dSAT has similar characteristics to VAT and is associated with cardiometabolic complications. ${ }^{7,9}$ In addition, it is suggested that men have a greater area of dSAT when compared to women, ${ }^{10-12}$ considering tissue-

Mailing Address: Aline Marcadenti

Rua Abílio Soares, 250. Postal Code: 04004-030, Paraíso, São Paulo, SP - Brazil.

E-mail: marcadenti.aline@gmail.com 
specific effects of sex hormones on the proliferation/ differentiation of adipocytes and the expansion of specific adipose tissue depots (visceral in males and gluteal in females)..$^{12,13}$

The golden standard for estimating dSAT is computed tomography. However, this method presents technical and cost difficulties that limit its use in clinical practice. ${ }^{10}$ Hence, predictive equations were created for the estimation of dSAT in men and women. The applicability of the Deep-Abdominal-Adipose-Tissue (DAAT) index was tested in the Brazilian population among subjects aged 30 to 80 years without CVDs, and the DAAT index proved to be positively related to type 2 diabetes mellitus (T2DM), ${ }^{7}$ while in individuals with obesity, it was correlated to body mass index (BMI), waist circumference, percentage of body fat, and free fat mass. ${ }^{14}$

It is known that dietary intake and physical activity levels modulate abdominal SAT concentrations. Modifications in lifestyle, based on changes in eating habits and practice of physical activity, are associated with a decrease in abdominal fat concentrations. ${ }^{15,16}$ Regarding the quality and quantity of the diet, abdominal obesity and SAT seems to be more strongly influenced by total dietary fat and a daily excess of energy consumed, as compared to the quality of the diet itself. ${ }^{17-20}$

To the best of our knowledge, the use of the DAAT index was not appropriately tested in a population with ACS, nor as regards its relationship with nutrients and energy intake. Therefore, the present study sought to evaluate the association between dSAT, estimated by the DAAT index, and the dietary intake of patients with ACS.

\section{Methods}

This was a cross-sectional study conducted in a tertiary hospital in Porto Alegre, Rio Grande do Sul, Brazil. This study evaluated patients with a medical diagnosis of ACS who received medial care in the Brazilian Unified Health System (SUS, in Portuguese) between July 2015 and September 2016. Inclusion criteria were individuals of both sexes, aged between 18 and 80 years, and who consented to participate in the study, signing the Informed Consent Form according to Resolution 466/2012. Individuals with cognitive impairment and without proper conditions of weight, height, and anthropometric measurements were excluded.

Demographic data (age, sex, and ethnicity), education (years of schooling), source of income, lifestyle characteristics (smoking, abusive alcohol consumption), previous medical diagnoses, and family history of heart attack or stroke were collected by means of a standardized questionnaire. The level of physical activity was assessed using a short version of the International Physical Activity Questionnaire (IPAQ).

Dietary data were obtained through a quantitative food frequency questionnaire (FFQ), containing 135 foods/ preparations and validated for the population of Porto Alegre, Rio Grande do Sul, Brazil. ${ }^{21}$ Food consumption during the 30 days before the hospital admission was investigated. Total energy intake (TEI, in kcal/day) consumed daily was calculated. The macronutrients of interest [carbohydrates, proteins, total fats, and saturated fatty acids (SFA), monounsaturated fatty acids (MUFA), and polyunsaturated fatty acids (PUFA)] were calculated in \% of TEI. Dietary calcium, zinc, sodium, potassium (in $\mathrm{mg} /$ day), dietary cholesterol (in $\mathrm{mg} /$ day), and dietary fiber (in g/day) were evaluated as well. Monthly intake was estimated and divided proportionally between the respective days. Analyses of all nutrients were carried out with the Avanutri Revolution $\AA^{\circledR}$ software (Rio de Janeiro, Brazil). The energy density (in $\mathrm{kcal} / \mathrm{kg}$ ) was obtained by dividing the TEI by the body mass.

The anthropometric evaluation was performed after the interview ended. Body mass (in kg) was measured with the participant using light clothing, and body height (in $\mathrm{m}$ ) was obtained using a stadiometer. Waist circumference (WC), hip circumference (HC), and neck circumference (NC) were measured with an inelastic tape measure of 0 to $143 \mathrm{~cm}$, with an accuracy of $1 \mathrm{~mm}$. BMI and waist-to-hip ratio (WHR) were calculated. General obesity was defined by a cut-off point of BMI $>30 \mathrm{~kg} / \mathrm{m}^{2}$; for WC, cutoff points were $>94 \mathrm{~cm}$ and $>80 \mathrm{~cm}$ for men and women, respectively (higher risk for CVD), and $W C \geq 102 \mathrm{~cm}$ for men and $\geq 88 \mathrm{~cm}$ for women (very high risk for CVD). For WHR, the cut-off point for men and women was $>1.00$ and $>0.85$, respectively. For the DAAT index calculation, the following mathematical formulas were used: DAAT $\left(\mathrm{cm}^{2}\right)=-382.9+[1.09 x$ body mass $(\mathrm{kg})]+[6.04 \times \mathrm{WC}(\mathrm{cm})]+29 \times$ BMI for men and DAAT $\left(\mathrm{cm}^{2}\right)=-278+[-0.86 \mathrm{x}$ body mass $(\mathrm{kg})]+[5.19 \mathrm{x}$ WC $(\mathrm{cm})]$ for women. ${ }^{10}$

Sample size calculation was performed through the WinPepi® program for Windows. Assuming a correlation coefficient ( $\mathrm{r}$ ) of 0.38 for the correlation between total fat consumption and central adiposity, ${ }^{22}$ a significance level of $5 \%$, and a power of $90 \%$, a sample of at least 69 patients would be required. 


\section{Statistical analysis}

Data were analyzed using the Statistical Package for Social Science program (SPSS version 17.0, Il, U.S.A.) for Windows. The normality of the data was evaluated according to the Kolmogorov-Smirnov test. Continuous variables were described in means and standard deviation (normal distribution) or in medians and interquartile range (non-normal distribution); categorical variables were described as absolute and percentage numbers. Unpaired Student's t-tests and the Wilcoxon-Mann-Whitney test were used for comparison between continuous variables, while Fisher's exact, or Pearson's Chi-square, test was used for comparisons between categorical variables. The Pearson correlation coefficient and partial correlation (adjusted for TEI) were used for correlations. A multiple linear regression analysis was used to evaluate possible associations after having checked all the necessary assumptions. The level of significance adopted was 0.05 .

The present study is part of a larger project entitled "Nutritional and anthropometric profile of patients with acute coronary syndrome (ACS)", which was approved by the Research Ethics Committee of Instituto de Cardiologia do RS / Fundação Universitária de Cardiologia (CAAE n ${ }^{\circ}$ 26591214.3.0000.5333) in 01/24/2014.

\section{Results}

The total sample consisted of 138 individuals, with a mean age of $61.2 \pm 10.8$ years, in which $61.6 \%$ were males $(\mathrm{n}=83), 80.4 \%(\mathrm{n}=111)$ of the sample were white, and $45 \%$ $(n=62)$ were retired. Regarding the medical diagnoses of previous disease, $38.4 \%(n=53)$ had T2DM, $69.6 \%(n=$ 96) had hypertension, $63.8 \%(n=88)$ had dyslipidemias, $7.2 \%(\mathrm{n}=10)$ had a history of previous stroke, and $63 \%$ $(\mathrm{n}=87)$ had a family history of heart attack. The mean BMI of the total sample was $28.2 \pm 5.3 \mathrm{~kg} / \mathrm{m}^{2}$.

Table 1 shows the characterization of the sample according to sex. Men presented a higher prevalence of smokers/ex-smokers and daily alcohol consumption. By contrast, women presented a higher prevalence of very high WC, higher values of WHR, and lower values of the DAAT index when compared to men.

The dietary intake in men and women is shown in Table 2. In comparison to women, men ingested larger daily amounts of energy, dietary cholesterol, sodium, potassium, and dietary fiber. No difference was found in relation to the consumption of other nutrients.
When correlating the DAAT index with nutrient intake, a positive and significant correlation was observed among protein intake $(\mathrm{r}=0.28, \mathrm{p}<0.001)$, total fat $(\mathrm{r}=0.25$, $\mathrm{p}=0.01)$, and MUFA $(\mathrm{r}=0.25, \mathrm{p}=0.003)$. No correlation was found between the DAAT index and the total energy intake, nor with other macronutrients, micronutrients, and dietary fiber intake. However, after adjusting for TEI, the DAAT index was positively correlated only with protein intake (partial correlation $[\mathrm{r}]=0.22, \mathrm{p}=0.01$ ) and MUFA (partial correlation $[\mathrm{r}]=0.18, \mathrm{p}=0.04$ ).

Table 3 shows the association between the DAAT index and the intake of proteins and MUFA. After adjusting for age, sex, TEI, alcohol consumption, and physical activity, only the female sex was negatively associated with the DAAT index $(\mathrm{P}<0.001)$, and physical inactivity (sedentary lifestyle) was positively associated with the DAAT index ( $\mathrm{P}<0.001)$. Macronutrients were not associated with DAAT index.

\section{Discussion}

The present study detected no associations among dSAT estimated by the DAAT index, daily energy, and nutrient intake in patients with, which only pointed to a sedentary lifestyle and the female sex .

In contrast to other studies, ${ }^{23-25}$ the female population evaluated in this protocol showed higher WHR values when compared to men. However, the age of the enrolled women indicates that they were in the postmenopausal period, and at this stage of life, women tend to accumulate more total abdominal adipose tissue ${ }^{26,27}$ and $\mathrm{VAT}^{28,29}$ which would contribute to an increase in WC and, consequently, in WHR. Another hypothesis is related to the loss of muscle mass, which depends on age. One study carried out in Japan showed that women aged $50-79$ years lost about $7.1 \%$ of their lower limb muscle mass with a concomitant increase of $65.3 \%$ in visceral fat, thus increasing the ratio between the circumferences. The study also showed that the loss of body muscle mass was negatively associated with visceral obesity in both sexes. ${ }^{30}$

The DAAT index was statistically different between men and women. This data corroborates with studies conducted in Asian, American, and Indian populations, which demonstrated a greater area of dSAT (obtained through computed tomography, ultrasonography, or DAAT) in men. ${ }^{11,12,25}$ The lower values of the DAAT index, plus higher WHR and WC in women, could be explained by the fact that women seem to have larger compartments of dSAT when compared to males. ${ }^{31}$ 
Table 1 - Characteristics of the sample according to sex $(n=138$; mean \pm SD or $n(\%)$ or median [IQR])

\begin{tabular}{|c|c|c|c|}
\hline & Men (n=85) & Women $(n=53)$ & p-value \\
\hline Age (years) & $60.1 \pm 10.7$ & $62.4 \pm 10.8$ & $0.32^{*}$ \\
\hline Education (years of schooling) & $8[5-11]$ & $5[4.75-11]$ & $0.28^{\mathbb{I}}$ \\
\hline Smoking & & & $0.14 \ddagger$ \\
\hline Smoker & $17(20)$ & $12(22.6)$ & \\
\hline Former smoker & $46(54)$ & $20(37.7)$ & \\
\hline Never smoked & $22(26)$ & $21(39.6)$ & \\
\hline Alcohol consumption & & & $0.01+$ \\
\hline Daily & $17(20)$ & $2(3.8)$ & \\
\hline Never/Almost never & $68(80)$ & $51(96)$ & \\
\hline Physical Activity & & & $0.93+$ \\
\hline Active & $41(48)$ & $26(49)$ & \\
\hline Irregularly Active/Sedentary & $44(52)$ & $27(51)$ & \\
\hline Body Mass Index (kg/m²) & $27.9 \pm 5.0$ & $28.5 \pm 5.6$ & $0.59^{*}$ \\
\hline Obesity (BMI $\geq 30$ kg/m²) & $25(29.5)$ & $20(37.7)$ & $0.35+$ \\
\hline Waist Circumference (cm) & $100.8 \pm 13.0$ & $98.4 \pm 13.0$ & $0.29^{*}$ \\
\hline WC classification & & & $<0.0001 \ddagger$ \\
\hline Normal & $22(26)$ & $2(3.8)$ & \\
\hline High & $25(29.4)$ & $7(13)$ & \\
\hline Very high & $38(45)$ & $44(83)$ & \\
\hline Waist-to-Hip ratio & $0.97 \pm 0.12$ & $1.05 \pm 0.10$ & $<0.0001^{*}$ \\
\hline Neck Circumference (cm) & $39.9 \pm 3.6$ & $36.9 \pm 3.3$ & $<0.0001^{*}$ \\
\hline DAAT $\left(\mathrm{cm}^{3}\right)$ & $304.1 \pm 95.0$ & $171.9 \pm 59.0$ & $<0.0001^{*}$ \\
\hline
\end{tabular}

Women showed a higher prevalence (83\%) when compared to men $(44.7 \%)$ of a very high risk for CVD according to their WC. This result corroborates with studies conducted in other countries, where values of WC considered to be very high were more prevalent in women. ${ }^{25,32,33}$ In a sample of individuals after a heart attack, no such difference was observed in WC values according to sex; however, it was found that WC values increased with age in both men and women. ${ }^{34}$

Regarding nutrient intake, our participants showed a daily energy consumption considered high in relation to their body mass, which could be related to obesity rates (general and abdominal). ${ }^{35}$ Similar to other studies conducted in individuals with heart disease, there was a high intake of SFA and dietary cholesterol, as well as a reduced intake of PUFA, MUFA, potassium, calcium, and dietary fiber. 22,36

The DAAT index correlated positively with proteins, total fats, SFA, and MUFA, but no association was observed after controlling for other variables. Among Israelis, there was also no association between dSAT assessed by computed tomography and dietary intake in general; however, there was a weak correlation between dSAT with the consumption of trans fatty acids. ${ }^{31}$ It is known that excessive energy intake is related to increased fat depots; ${ }^{35}$ however, excessive intake of SFA may contribute substantially to adipose cell hyperplasia in the abdominal region; conversely, PUFA tends to contribute to a reduction in the number of adipose cells. ${ }^{37}$ 


\begin{tabular}{|c|c|c|c|c|}
\hline Nutrients & Entire sample (n=138) & $\begin{array}{l}\text { Men } \\
(n=85)\end{array}$ & $\begin{array}{l}\text { Women } \\
(n=53)\end{array}$ & p-value \\
\hline Total energy intake (kcal) & $2330.9 \pm 834.9$ & $2470.1 \pm 861.3$ & $2107.6 \pm 745.5$ & $0.01^{*}$ \\
\hline Energy density (kcal/kg) & $31.3 \pm 12.6$ & $31.5 \pm 13.1$ & $31.1 \pm 12.0$ & $0.86^{*}$ \\
\hline Carbohydrate (\% of TEI) & $54.8 \pm 7.1$ & $54.5 \pm 6.8$ & $55.3 \pm 7.5$ & $0.55^{*}$ \\
\hline Protein (\% of TEI) & $16.3 \pm 3.1$ & $16.5 \pm 2.8$ & $15.9 \pm 3.5$ & $0.29^{*}$ \\
\hline Total fats (\% of TEI) & $28.8 \pm 5.2$ & $28.7 \pm 5.0$ & $28.82 \pm 5.6$ & $0.92^{*}$ \\
\hline SFA ( $\%$ of TEI) & $8.5 \pm 2.7$ & $8.8 \pm 2.6$ & $8.1 \pm 2.7$ & $0.15^{*}$ \\
\hline PUFA (\% of TEI) & $2.9 \pm 1.0$ & $3.0 \pm 1.0$ & $2.9 \pm 1.0$ & $0.54^{*}$ \\
\hline MUFA (\% of TEI) & $6.9 \pm 2.0$ & $7.1 \pm 2.2$ & $6.5 \pm 1.8$ & $0.12^{*}$ \\
\hline Dietary cholesterol (mg) & $263[185.15-374.6]$ & 270.4 [204.1-392.4] & $233.6[156.7-348]$ & $0.04 \dagger$ \\
\hline Sodium (mg) & 1981.5 [1597.9-2667.1] & 2201.4 [1742.7-2782.5] & 1655.5 [1401.9-2278.3] & $<0.001+$ \\
\hline Potassium (mg) & 2128.3 [1884.1-2768.2] & 2183.4 [1966-2843.2] & 2000.7 [1781-2576.9] & $0.04 \dagger$ \\
\hline Calcium (mg) & 691.8 [380.3-940.7] & 627.8 [374.3-927.6] & 730.8 [417.7-947.6] & $0.67 \dagger$ \\
\hline Zinc (mg) & $10.0 \pm 3.8$ & $10.3 \pm 3.7$ & $9.4 \pm 3.8$ & $0.14^{*}$ \\
\hline Dietary fibers (g) & $17.4[14.2-23.2]$ & $17.9[15-24.6]$ & 16.5 [14.1-21.5] & $0.09+$ \\
\hline
\end{tabular}

Table 3 - Association between the DAAT index and macronutrients [multiple linear regression adjusted for sex, total energy intake (TEI) alcohol consumption, and physical activity level]

\begin{tabular}{lcc}
\hline & Beta; SE (95\% CI) & p-value \\
\hline Age, in years & $-0.044 ; 0.662(-1.35-1.27)$ & 0.95 \\
\hline Female sex & $-129.84 ; 14.23(-158.12--101.56)$ & $<0.001$ \\
\hline Daily consumption of alcohol & $23.02 ; 20.48(-17.49-63.52)$ & 0.26 \\
\hline Sedentary lifestyle & $57.99 ; 13.34(31.60-84.39)$ & $<0.001$ \\
\hline Total energy intake (kcal) & $-0.01 ; 0.02(-0.29-1.40)$ & 0.20 \\
\hline Proteins (\% of TEI) & $0.33 ; 0.23(-0.12-0.78)$ & 0.20 \\
\hline MUFA (\% of TEI) & $4.63 ; 3.30(-1.89-11.15)$ & 0.16 \\
\hline SE: standard error; CI: confidence interval; MUFA: monounsaturated fatty acids; TEI: total energy intake. &
\end{tabular}

In the present study, a positive association was observed between dSAT and a sedentary lifestyle. The practice of regular physical activity exerts positive effects on the decrease of SAT and VAT, in addition to preventing the increase in these compartments over time. ${ }^{18,19}$ The effects of a one-year lifestyle modification program on body fat distribution were assessed among Canadians, and the results showed that physical exercise significantly reduced VAT, dSAT, and sSAT. ${ }^{38}$ 
Among the limitations of this study, it is important to mention its cross-sectional design (patients were evaluated in a single moment). Regarding the FFQ, the limitations are related to memory bias and flat slope syndrome, and this may not represent the patient's general eating habits, since only the 30 days preceding the cardiac event were evaluated. In this sense, the estimate of habitual intake may not be reliable when applying a single FFQ. ${ }^{39,40}$ There are also limitations on the IPAQ, which considers only the prior seven days to assess the level of physical activity. Some patients, however, had already presented limitations in physical performance more than seven days before the coronary event, and light activities may be considered by them as intense and vigorous activities considering a greater effort and fatigue due to illness.

\section{Conclusions}

We concluded that dSAT, estimated by the DAAT index, was not associated with total energy intake, macronutrients, and micronutrients, but rather with the female sex (negatively) and with a sedentary lifestyle (positively), suggesting that women and active people have a smaller area of dSAT. Further studies are needed to confirm our findings.

Data Sharing: Data can be provided by Prof. Aline Marcadenti, who can be reached by e-mail: marcadenti. aline@gmail.com.

\section{References}

1. World Health Organization. Cardiovascular diseases [Internet]. Geneva: WHO; 2021 [cited 2021 Jun 4]. Available from https://www.who.int/ health-topics/cardiovascular-diseases\#tab=tab_1.

2. Dessotte CA, Dantas RA, Schmidt A. Patients' symptoms before a first hospitalization due to Acute Coronary Syndrome. Rev Esc Enferm USP. 2011;45(5):1097-104. doi: 10.1590/s0080-62342011000500010.

3. Santos MCB, Vieira JAM, César BN, Novaes MRCG. Hábitos e perfil socioeconômico do paciente aterosclerótico no Brasil. Comun. ciênc. saúde 2012;22(3):247-56.

4. Atkins JL, Whincup PH, Morris RW, Lennon LT, Papacosta O, Wannamethee SG. Dietary patterns and the risk of CVD and all-cause mortality in older British men. Br J Nutr. 2016;116(7):1246-55. doi: 10.1017/ S0007114516003147.

5. Brasil. Ministério da Saúde. Secretaria de Vigilância em Saúde. Departamento de Análise em Saúde e Vigilância de Doenças Não Transmissíveis. Vigitel Brasil 2019: vigilância de fatores de risco e proteção para doenças crônicas por inquérito telefônico: estimativas sobre frequência e distribuição sociodemográfica de fatores de risco e proteção para doenças crônicas nas capitais dos 26 estados brasileiros e no Distrito Federal em 2019. Brasília: Ministério da Saúde; 2020

6. Merry AH, Boer JM, Schouten LJ, Feskens EJ, Verschuren WM, Gorgels $\mathrm{AP}$, et al. Smoking, alcohol consumption, physical activity, and family

\section{Potential Conflict of Interest}

No potential conflict of interest relevant to this article was reported.

\section{Sources of Funding}

There were no external funding sources for this study.

\section{Study Association}

This study is not associated with any thesis or dissertation work.

\section{Ethics approval and consent to participate}

This study was approved by the Ethics Committee of the Instituto de Cardiologia do RS / Fundação Universitária de Cardiologia under the protocol number CAAE: 26591214.3.0000.5333. All the procedures in this study were in accordance with the 1975 Helsinki Declaration, updated in 2013. Informed consent was obtained from all participants included in the study.

\section{Author contributions}

Analysis and interpretation of the data: Marcadenti A. Writing of the manuscript: Stein E. Critical revision of the manuscript for intellectual content: Stein E, Barbiero S, Portal VL, Luz V, Marcadenti A.

history and the risks of acute myocardial infarction and unstable angina pectoris: a prospective cohort study. BMC Cardiovasc Disord. 2011;11:13. doi: 10.1186/1471-2261-11-13.

7. Impérico A, Marcadenti A. Measurements of visceral adiposity, type2 diabetes and risk for cardiovascular disease among Brazilian men and women. J Endocrinol Diab. 2015; 2(1):1-5. doi: 10.15226/2374$6890 / 2 / 1 / 00114$

8. Haftenberger M, Mensink GB, Vogt S, Thorand B, Peters A, Herzog B, et al. Changes in Waist Circumference among German adults over time - Compiling results of seven prospective cohort studies. Obes Facts. 2016;9(5):332-43. doi: 10.1159/000446964.

9. Després JP, Prud'homme D, Pouliot MC, Tremblay A, Bouchard C. Estimation of deep abdominal adipose-tissue accumulation from simple anthropometric measurements in men. Am J Clin Nutr. 1991;54(3):471-7. doi: 10.1093/ajcn/54.3.471.

10. Brundavani V, Murthy SR, Kurpad AV. Estimation of deep-abdominaladipose-tissue (DAAT) accumulation from simple anthropometric measurements in Indian men and women. Eur J Clin Nutr. 2006;60(5):65866. doi: 10.1038/sj.ejen.1602366.

11. Kohli S, Sniderman AD, Tchernof A, Lear SA. Ethnic-specific differences in abdominal subcutaneous adipose tissue compartments. Obesity. 2010;18(11):2177-83. doi: 10.1038/oby.2010.94. 
12. Marinou K, Hodson L, Vasan SK, Fielding BA, Banerjee R, Brismar K, et al. Structural and functional properties of deep abdominal subcutaneous adipose tissue explain its association with insulin resistance and cardiovascular risk in men. Diabetes Care. 2014;37(3):821-9. doi: 10.2337/ dc13-1353.

13. Mayes JS, Watson GH. Direct effects of sex steroid hormones on adipose tissues and obesity. Obes Rev. 2004;5(4):197-216. doi: 10.1111/j.1467789X.2004.00152.x.

14. Rocha DRW, Jorge AR, Braulio VB, Arbex AK, Marcadenti A. Visceral adiposity measurements, metabolic and inflammatory profi le in obese patients with and without Type 2 diabetes mellitus: a crosssectional analysis. Curr Diabetes Rev. 2017;13(1):11-8. doi: 10.2174/157339981266 6151015115924.

15. Laaksonen DE, Kainulainen S, Rissanen A, Niskanen L. Relationships between changes in abdominal fat distribution and insulin sensitivity during a very low calorie diet in abdominally obese men and women. Nutr Metab Cardiovasc Dis. 2003;13(6):349-56. doi: 10.1016/s09394753(03)80003-0.

16. Friedenreich CM, Neilson HK, O'Reilly R, Duha A, Yasui Y, Morielli $\mathrm{AR}$, et al. Effects of a high vs moderate volume of aerobic exercise on adiposity outcomes in postmenopausal women: a randomized clinical trial. JAMA Oncol. 2015;1(6):766-76. doi: 10.1001/jamaoncol.2015.2239.

17. Bailey BW, Sullivan DK, Kirk EP, Donnelly JE. Dietary predictors of visceral adiposity in overweight young adults. Br J Nutr. 2010;103(12):1702-5. doi: 10.1017/S0007114509993771.

18. König D, Zdzieblik D, Deibert P, Berg A, Gollhofer A, Büchert M. Internal fat and cardiometabolic risk factors following a meal-replacement regimen vs. comprehensive lifestyle changes in obese subjects. Nutrients. 2015;7(12):9825-33. doi: 10.3390/nu7125500.

19. Fischer K, Rüttgers D, Müller HP, Jacobs G, Kassubek J, Lieb W, et al. Association of habitual patterns and types of physical activity and inactivity with MRI-determined total volumes of visceral and subcutaneous abdominal adipose tissue in a general white population. PLoS One. 2015;10(11):e0143925. doi: 10.1371/journal.pone.0143925.

20. Fischer K, Moewes D, Koch M, Müller HP, Jacobs G, Kassubek J, et al. MRI-determined total volumes of visceral and subcutaneous abdominal and trunk adipose tissue are differentially and sex-dependently associated with patterns of estimated usual nutrient intake in a northern German population. Am J Clin Nutr. 2015;101(4):794-807. doi: 10.3945/ ajcn.114.101626.

21. Henn RL, Fuchs SC, Moreira LB, Fuchs FD. Development and validation of a food frequency questionnaire (FFQ-Porto Alegre) for adolescent, adult and elderly populations from Southern Brazil. Cad Saude Publica. 2010;26(11):2068-79. doi: 10.1590/s0102-311x2010001100008.

22. Pinho PM, Silva ACM, Araújo MS, Reis CP, Almeida SS, Barros RCA, et al. Correlação entre Variáveis Nutricionais e Clínicas de Idosos Cardiopatas. Rev Bras Cardiol. 2012;25(2):132-40.

23. Sauvageot N, Leite S, Alkerwi A, Sisanni L, Zannad F, Saverio S, et al. Association of empirically derived dietary patterns with cardiovascular risk factors: a comparison of PCA and RRR methods. PLoS One. 2016;11(8):e0161298. doi: 10.1371/journal.pone.0161298.

24. Oliveira MA, Fagundes RL, Moreira EA, Trindade EB, Carvalho Td. Relation between anthropometric indicators and risk factors for cardiovascular disease. Arq Bras Cardiol. 2010;94(4):478-85. doi: 10.1590/ s0066-782x2010005000012.

25. Sahoo JP, Kumari S, Jain S. Effect of gender on the total abdominal fat, intra-abdominal adipose tissue and abdominal sub-cutaneous adipose tissue among Indian hypertensive patients. J Clin Diagn Res. 2016;10(4):OM01-3. doi: 10.7860/JCDR/2016/17594.7601.
26. Machado PA, Sichieri R. Waist-to-hip ratio and dietary factors in adults. Rev Saude Publica. 2002;36(2):198-204. doi: 10.1590/s003489102002000200012.

27. Goh VHH, Hart WG. Excess fat in the abdomen but not general obesity is associated with poorer metabolic and cardiovascular health in premenopausal and postmenopausal Asian women. Maturitas. 2018;107:33-8. doi: 10.1016/j.maturitas.2017.10.002.

28. Carranza-Lira S, Azpilcueta YM, Ortiz SR. Relation between visceral fat and carotid intimal media thickness in Mexican postmenopausal women: a preliminary report. Prz Menopauzalny. 2016;15(2):81-4. doi: 10.5114/ pm.2016.61189.

29. Pitanga FJG, Pitanga CPS, Gabriel RECD, Beck CC, Moreira MHR Anthropometry to identify high visceral fat area in postmenopausal women. Nutr Hosp. 2015;32(6):2535-9. doi: 10.3305/nh.2015.32.6.9813.

30. Yamada M, Moriguch Y, Mitani T, Aoyama T, Arai H. Age-dependent changes in skeletal muscle mass and visceral fat area in Japanese adults from 40 to 79 years-of-age. Geriatr Gerontol Int. 2014;14 (Suppl 1):8-14. doi: 10.1111/ggi.12209.

31. Golan R, Shelef I, Rudich A, Gepner Y, Shemesh E, Chassidim Y, et al. Abdominal superficial subcutaneous fat: a putative distinct protective fat subdepot in Type 2 diabetes. Diabetes Care. 2012;35(3):640-7. doi: $10.2337 /$ dc11-1583

32. Oksuzyan A, Shkolnikova M, Vaupel JW, Christensen K, Shkolnikov VM. Sex differences in biological markers of health in the study of stress, aging and health in Russia. PLoS One. 2015;10(6):e0131691. doi: 10.1371/ journal.pone.0131691.

33. Okop KJ, Levitt N, Puoane T. Factors associated with excessive body fat in men and women: cross-sectional data from black south Africans living in a rural community and an urban township. PLoS One. 2015;10(10):e0140153. doi: 10.1371/journal.pone.0140153.

34. Zeller M, Steg PG, Ravisy J, Lorgis L, Laurent Y, Sicard P, et al. Relation between body mass index, waist circumference, and death after acute myocardial infarction. Circulation. 2008;118(5):482-90. doi: 10.1161/ CIRCULATIONAHA.107.753483.

35. Church T, Martin CK. The obesity epidemic: a consequence of reduced energy expenditure and the uncoupling of energy intake? Obesity. 2018;26(1):14-6. doi: 10.1002/oby.22072.

36. Szot W, Zając J, Kostkiewicz M, Kolarzyk E. Dietary patterns seem to influence the development of perfusion changes in cardiac syndrome $\mathrm{X}$ patients. Adv Clin Exp Med. 2015;24(3):453-62. doi: 10.17219/acem/34475.

37. Garaulet M, Hernandez-Morante JJ, Lujan J, Tebar FJ, Zamora S. Relationship between fat cell size and number and fatty acid composition in adipose tissue from different fat depots in overweight/obese humans. Int J Obes (Lond). 2006;30(6):899-905. doi: 10.1038/sj.ijo.0803219.

38. Villeneuve N, Pelletier-Beaumont E, Nazare JA, Lemieux I, Alméras N, Bergeron J, et al. Interrelationships between changes in anthropometric variables and computed tomography indices of abdominal fat distribution in response to a 1-year physical activity-healthy eating lifestyle modification program in abdominally obese men. Appl Physiol Nutr Metab. 2014;39(4):503-11. doi: 10.1139/apnm-2013-0270.

39. Kobayashi T, Kamimura M, Imai S, Toji C, Okamoto N, Fukui M, et al. Reproducibility and validity of the food frequency questionnaire for estimating habitual dietary intake in children and adolescents. Nutr J. 2011;10:27. doi: 10.1186/1475-2891-10-27.

40. Freedman LS, Midthune D, Arab L, Prentice RL, Subar AF, Willett $\mathrm{W}$, et al. Combining a food frequency questionnaire with 24-hour recalls to increase the precision of estimation of usual dietary intakesevidence from the validation studies pooling project. Am J Epidemiol. 2018;187(10):2227-32. doi: 10.1093/aje/kwy126. 